ISSN 1029-8940 (Print)

ISSN 2524-230X (Online)

УДК 581.192:615.322

https://doi.org/10.29235/1029-8940-2021-66-3-263-270

Поступила в редакцию 18.03.2021

Received 18.03.2021

\title{
Н. Ю. Адамцевич ${ }^{1}$, Е. В. Феськова ${ }^{1}$, В. В. Титок ${ }^{2}$, В. С. Болтовский ${ }^{1}$
}

${ }^{1}$ Белорусский государственный технологический университет, Минск, Республика Беларусь

${ }^{2}$ Центральный ботанический сад НАН Беларуси, Минск, Республика Беларусь

\section{ДИНАМИКА НАКОПЛЕНИЯ ФЛАВОНОИДОВ, МАКРО- И МИКРОЭЛЕМЕНТОВ В ЛИСТЬЯХ ВОРОБЕЙНИКА ЛЕКАРСТВЕННОГО (LITHOSPERMUM OFFICINALE L.) В РАЗЛИЧНЫЕ ФЕНОЛОГИЧЕСКИЕ ФАЗЫ}

Аннотация. В работе изучена динамика накопления флавоноидов в листьях воробейника лекарственного (Lithospermum officinale L.) второго года культивирования в различные фенологические фазы. Максимальное содержание флавоноидов наблюдалось в период цветения. Показано, что качественный состав экстрактов листьев воробейника лекарственного в различные фенологические фазы изменялся незначительно. На каждом этапе развития растения идентифицирован флавоноид изокверцитрин, максимальное его количество отмечалось в фазу цветения.

При сравнительной оценке элементного состава листьев воробейника лекарственного в зависимости от фенологической фазы отмечено высокое содержание кальция, калия и кремния во все фазы развития растения. Определено количественное содержание 11 макро- и микроэлементов.

Ключевые слова: воробейник лекарственный (Lithospermum officinale L.), флавоноиды, изокверцитрин, фенологические фазы, высокоэффективная жидкостная хромато-масс-спектрометрия, макроэлементы, микроэлементы

Для цитирования: Динамика накопления флавоноидов, макро- и микроэлементов в листьях воробейника лекарственного (Lithospermum officinale L.) в различные фенологические фазы / Н. Ю. Адамцевич [и др.] // Вес. Нац. акад. навук Беларусі. Сер. біял. навук. - 2021. - Т. 66, № 3. - С. 263-270. https://doi.org/10.29235/1029-8940-2021-66-3$263-270$

\author{
Natallia Yu. Adamtsevich ${ }^{1}$, Alena V. Feskova ${ }^{1}$, Vladimir V. Titok ${ }^{2}$, Valeriy S. Boltovskiy ${ }^{1}$ \\ ${ }^{1}$ Belarusian State Technological University, Minsk, Republic of Belarus \\ ${ }^{2}$ Central Botanical Garden of the National Academy of Sciences of Belarus, Minsk, Republic of Belarus
DYNAMICS OF THE ACCUMULATION OF FLAVONOIDS, MACRO- AND MICROELEMENTS
IN THE LEAVES OF THE LITTLEWALE (LITHOSPERMUM OFFICINALE L.) IN DIFFERENT PHENOLOGICAL PHASES

\begin{abstract}
The dynamics of accumulation of flavonoids in the leaves of the littlewale (Lithospermum officinale L.) of the second year of cultivation in various phenological phases was studied. The maximum content of flavonoids was observed during the flowering phase. It was shown that the qualitative composition of the extracts of the leaves of the common sparrow in different phenological phases was changed insignificantly. At each stage of plant development, the flavonoid isoquercitrin was identified, the maximum amount of which was observed in the flowering phase.

A comparative assessment of the elemental composition of the leaves of the littlewale is carried out, depending on the phenological phase. The quantitative content of 11 macro- and microelements has been determined. A high content of calcium, potassium and silicon was noted in each phase of plant development.

Keywords: littlewale (Lithospermum officinale L.), flavonoids, isoquercitrin, phenological phases, high performance liquid chromatography-mass spectrometry, macroelements, microelements

For citation: Adamtsevich N. Yu., Feskova A. V., Titok V. V., Boltovskiy V. S. Dynamics of the accumulation of flavonoids, macro- and microelements in the leaves of the littlewale (Lithospermum officinale L.) in different phenological phases. Vestsi Natsyyanal'nai akademii navuk Belarusi. Seryya biyalagichnykh navuk = Proceedings of the National Academy of Sciences of Belarus. Biological series, 2021, vol. 66, no. 3, pp. 263-270 (in Russian). https://doi.org/10.29235/1029-89402021-66-3-263-270
\end{abstract}

Введение. Помимо первичных метаболитов - углеводов, аминокислот, жирных кислот, хлорофиллов, цитохромов, нуклеотидов, а также соединений, являющихся интермедиатами различных метаболических реакций, растения содержат вещества, которые не участвуют в основном обмене. Их принято называть вторичными метаболитами либо веществами вторичного происхождения [1-3]. 
Последние десятилетия характеризуются бурным развитием разделов фитофизиологии и фармакологии, связанных с изучением веществ вторичного происхождения растений. Наиболее распространенными среди них являются разнообразные флавоноиды. Данный класс соединений играет важную роль в метаболизме растений и принимает участие в их росте и развитии. Большинство флавоноидов придают яркую окраску цветкам и плодам. Это привлекает насекомыхопылителей, что способствует размножению и распространению растений [4-6]. Антистрессовая (защитная) функция данного класса соединений против различных негативных факторов внешней среды (механическое повреждение, инфекции, насекомые, ультрафиолетовое излучение, температурный стресс) заключается в их участии в окислительно-восстановительных процессах, антибиотической активности, способности связываться с протеинами, служить материалом для построения клеточной стенки [3,5-8]. Протекторная функция флавоноидов в тканях растений (против любых биотических и абиотических стрессоров) дает основание рассматривать их в роли универсальных физиологических адаптогенов к неблагоприятным факторам среды [5].

В растении флавоноиды локализуются преимущественно в листьях, цветках и плодах, реже в стеблях и подземных органах. Обычно данные соединения сосредоточены в вакуолях, хотя некоторые из них обнаружены в хромопластах и хлоропластах растительной ткани $[1,3]$.

На состав и накопление биологически активных веществ (БАВ) в растении оказывают влияние генотип, фаза развития растения, условия произрастания и множество других факторов. Общих закономерностей, влияющих на изменение качественного и количественного состава БАВ, в онтогенезе растения не выявлено [2].

Изучение динамики накопления флавоноидов имеет как практическое, так и теоретическое значение. С теоретической точки зрения выясняется биохимическая роль флавоноидов в период роста и развития растения, с практической - устанавливаются оптимальные сроки сбора растительного сырья (период максимального накопления БАВ) в целях рационального использования ресурсов лекарственного растения.

Воробейник лекарственный (Lithospermum officinale L.) - вид двудольных растений рода Воробейник (Lithospermum) семейства Бурачниковые (Boraginaceae), включен в 3-е издание Красной книги Республики Беларусь [9]. С целью сохранения и распространения воробейника лекарственного в качестве лекарственного и медоносного вида он культивируется в Центральном ботаническом саду НАН Беларуси (ЦБС).

Воробейник лекарственный является многолетним растением с утолщенным, прямостоячим, разветвленным стеблем, ланцетными листьями, расположенными поочередно. Сверху листва окрашена в темный цвет, снизу - светло-зеленая. Цветки мелкие, желтоватые. Цветет в июнеиюле [10].

При исследовании химического состава некоторых видов лекарственных растений из коллекции ЦБС в экстракте листьев воробейника лекарственного обнаружен изокверцитрин [11], который является одним из ключевых флавоноидов, способствующих регенерации тканей $[12,13]$. Таким образом, воробейник лекарственный представляет интерес и для медицинской практики.

Лекарственные растения способны накапливать жизненно необходимые макро- и микроэлементы, которые оказывают определенное влияние на рост и развитие растения, активизируют ферментные системы, играют важную роль в пластических процессах и поддержании кислотнощелочного баланса [14]. Кроме того, лечебный эффект содержащихся в растительном сырье БАВ может успешно сочетаться с действием микроэлементов, которые могут стимулировать или ингибировать процессы роста, развития и репродуктивную функцию растений, действуя через ферментную систему или непосредственно связываясь с биополимерами растений [15].

В работе [16] при определении элементного состава некоторых видов растений в воробейнике лекарственном преобладающими элементами являлись кальций, калий и кремний.

Цель работы - изучение динамики накопления флавоноидов и исследование элементного состава листьев воробейника лекарственного в различные фенологические фазы.

Объекты и методы исследования. Объектом исследования являлись листья воробейника лекарственного второго года культивирования из коллекции лекарственных растений ЦБС, собранные в различные фенологические фазы (урожай 2020 г.). 
Растительное сырье собирали вручную, раскладывали тонким слоем и сушили естественным путем без доступа прямых солнечных лучей. Влажность сырья определяли согласно методике, приведенной в Государственной фармакопее Республики Беларусь (ГФ РБ) [17].

Измельченное (фракция 2-3 мм) сухое растительное сырье экстрагировали в течение 40 мин при ранее подобранных оптимальных условиях: 50 \%-ный этиловый спирт, температура $65-70{ }^{\circ} \mathrm{C}$, соотношение массы сырья к объему экстрагента 1:20 [18].

Общее содержание флавоноидов в экстрактах определяли с помощью спектрофотометрического метода, основанного на реакции комплексообразования флавоноидов с хлоридом алюминия (методика приведена в работе [18]). Оптическую плотность растворов измеряли на спектрофотометре SPECORD 200 (Analytik Jena, Германия) при длине волны 411 нм в кювете с толщиной слоя 10 мм.

Водно-спиртовые экстракты листьев воробейника лекарственного анализировали с помощью хромато-масс-спектрометра жидкостного (Waters, CША), колонка - BDS HYPERSIL $\mathrm{C}_{18}$ $250 \times 4,6$ мм, 5 мкм (Thermo Electron Corporation, США). В качестве подвижной фазы использовали ацетонитрил и воду с $1 \%$-ной муравьиной кислотой в соотношении 20:80 в изократическом режиме при скорости элюирования 1 мл/мин. Регистрацию хроматографического разделения осуществляли с помощью диодно-матричного детектора в диапазоне длин волн 200-700 нм и масс-детектора с электроспрей-ионизацией (ESI). Регистрацию масс-спектров проводили в области отрицательных и положительных ионов при следующих параметрах: напряжение на капилляре -3 кВ, напряжение на конусе - $20 \mathrm{~B}$, напряжение на экстракторе - $3 \mathrm{~B}$, температура десольватации $-350{ }^{\circ} \mathrm{C}$, температура источника $-130{ }^{\circ} \mathrm{C}$, общий расход инертного газа (азота) 480 л/ч. Обработку результатов осуществляли при помощи программного обеспечения Mass Lynx. Для качественного и количественного определения изокверцитрина использовали стандартный раствор коммерческого препарата изокверцитрина (Sigma, Германия).

Определение общего количества золы выполняли согласно методике, приведенной в ГФ ГБ [17]. Элементный состав образцов золы изучали с помощью сканирующего электронного микроскопа JSM-5610 LV с системой химического анализа EDX JED-2201 (JEOL, Япония).

Bсе анализы проводили в трехкратной повторности. Для статистической обработки полученных результатов использовали программу Microsoft Office Excel 2007. Значения статистически значимо различались при $p<0,05$.

Результаты и их обсуждение. Поскольку флавоноиды участвуют во всех процессах роста и развития растения, их содержание в различные фенологические фазы варьируется.

На рис. 1 представлены результаты изучения динамики накопления флавоноидов в листьях воробейника лекарственного на разных этапах развития растения.

В фазу вегетации содержание флавоноидов в листьях воробейника лекарственного составляло $1,06 \pm 0,05 \%$ от массы абсолютно сухого сырья. В период бутонизации (вторая половина мая) концентрация флавоноидов увеличилась до $1,83 \pm 0,09 \%$. В фазу цветения (июнь) содержание данного класса БАВ продолжало увеличиваться и в период массового цветения (середина июня) достигло $2,53 \pm 0,11 \%$. В фазу плодоношения (начало июля) количество флавоноидов уменьшилось незначительно, однако к концу июля составило $2,21 \pm 0,09$ \%. Таким образом, максимальное содержание флавоноидов в листьях воробейника лекарственного наблюдалось в фазу массового цветения.

Функции флавоноидов в период роста и развития растения довольно значимы. Например, благодаря способности поглощать ультрафиолетовое излучение (330-350 нм) и часть видимого света (520-560 нм) они защищают растительные ткани от избыточной радиации. Флавоноиды являются фактором устойчивости растений к поражению некоторыми травоядными насекомыми, патогенными бактериями и грибами. Возможно, высокое содержание флавоноидов в листьях воробейника лекарственного в фазу цветения и начала плодоношения может быть связано с их защитными функциями и необходимостью выживания растения на таких важных стадиях развития.

Исследование образцов методом ВЭЖХ-МС показало, что в экстрактах листьев воробейника лекарственного в течение сезонного развития имеется до 15 компонентов (рис. 2). 


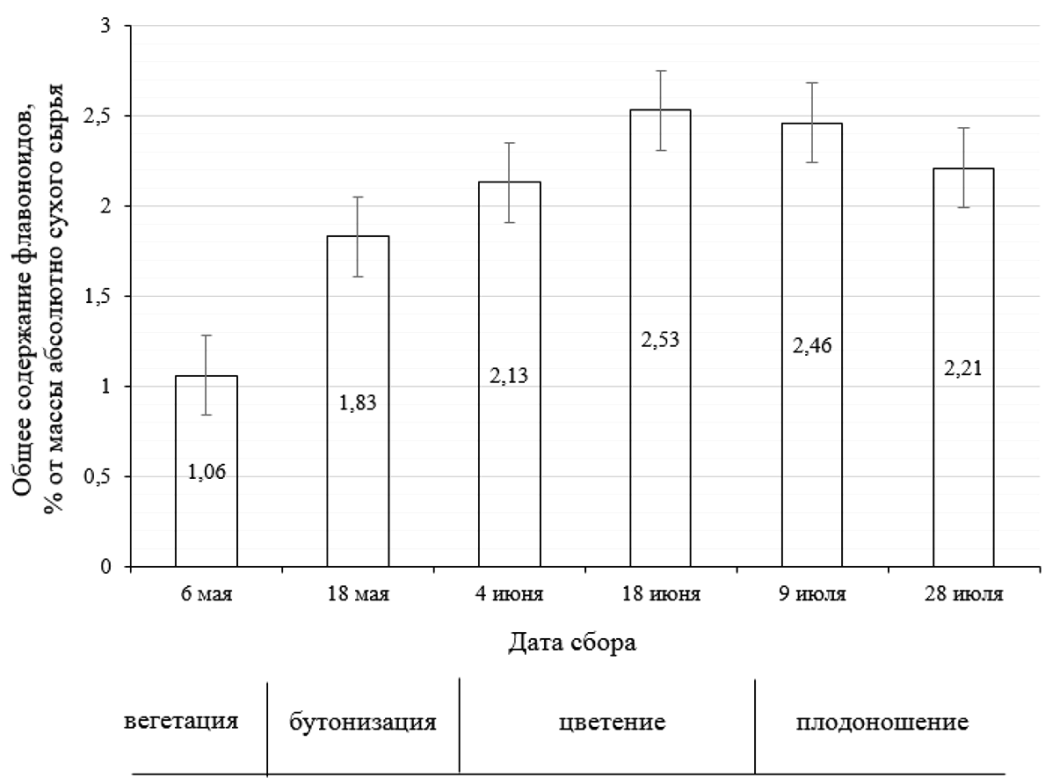

Рис. 1. Динамика накопления флавоноидов в листьях Lithospermum officinale L. в различные фенологические фазы

Fig. 1. The dynamics of accumulation of flavonoids in the leaves of the Lithospermum officinale L. in various phenological phases

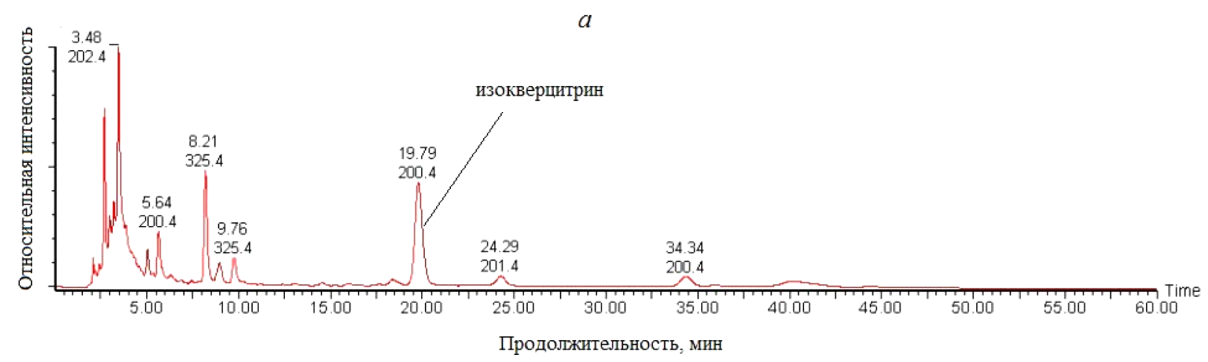

$b$
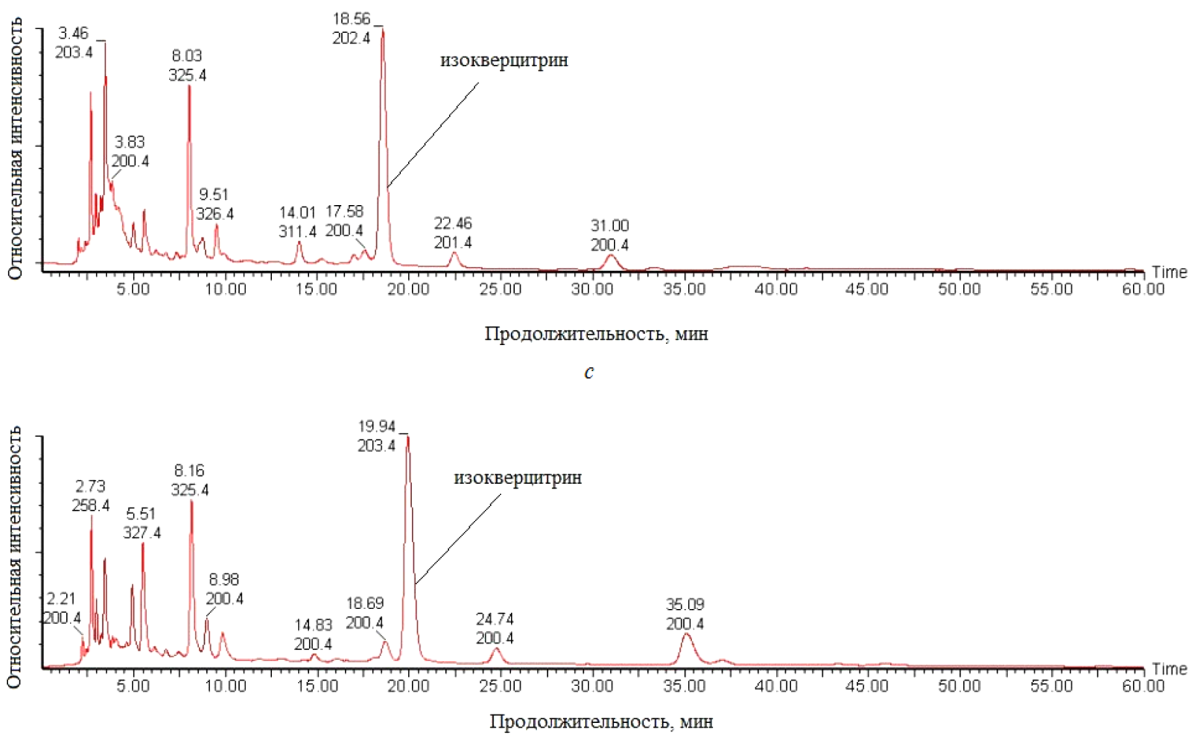

Рис. 2. Хроматограммы экстрактов листьев Lithospermum officinale L. в различные фенологические фазы ( $a$ - фаза бутонизации, $b$ - фаза цветения, $c$ - фаза плодоношения)

Fig. 2. Chromatograms of extracts of the leaves of the Lithospermum officinale L. in various phenological phases ( $a$ - budding phase, $b$ - flowering phase, $c$ - fruiting phase) 
При сравнении хроматограмм экстрактов установлено, что в различные фенологические фазы число пиков, их относительное расположение на хроматограмме и соотношение площадей изменялись незначительно.

В листьях воробейника лекарственного содержится флавоноид изокверцитрин - гликозид кверцетина (углеводная часть представлена глюкозой). Данный флавоноид идентифицирован во всех образцах, однако по мере развития растения его количественное содержание изменялось (табл. 1).

Т а б л и ц а 1. Содержание изокверцитрина в листьях Lithospermum officinale L. в различные фенологические фазы

$\mathrm{T}$ a b $1 \mathrm{e}$ 1. Isoquercitrin content in the leaves of the Lithospermum officinale $\mathbf{L}$. in various phenological phases

\begin{tabular}{|l|c|}
\hline \multicolumn{1}{|c|}{ Фенологическая фаза } & Содержание изокверцитрина, мг/г абсолютно сухого сырья \\
\hline Бутонизация & $2,09 \pm 0,09$ \\
\hline Цветение & $4,22 \pm 0,18$ \\
\hline Плодоношение & $3,64 \pm 0,16$ \\
\hline
\end{tabular}

Как видно из табл. 1, наибольшее содержание изокверцитрина наблюдалось в экстрактах листьев воробейника лекарственного в фазу цветения.

Для полноценного развития растения необходимы макро- и микроэлементы, так как они являются составляющими многих компонентов, включая белки, нуклеиновые кислоты и хлорофилл, важны для таких физиологических процессов, как дыхание, поддержание осмотического давления, входят в состав ферментов, которые, являясь катализаторами биохимических процессов, повышают активность последних.

В листьях воробейника лекарственного определено количественное содержание 11 макрои микроэлементов (табл. 2). При сравнительном анализе исследуемых образцов отмечено варьирование в содержании отдельных важных элементов в зависимости от фазы развития растения.

Из представленных в табл. 2 данных следует, что в листьях воробейника лекарственного преобладают такие элементы, как кальций, калий и кремний, что соответствует литературным данным.

Т а б л и ц а 2. Содержание макро- и микроэлементов в золе листьев Lithospermum officinale L. в различные фенологические фазы (г/100 г золы)

$\mathrm{T}$ a $\mathrm{b} 1 \mathrm{e}$ 2. Content of macro- and microelements in the leaves of the Lithospermum officinale $\mathrm{L}$. in various phenological phases $(\mathrm{g} / 100 \mathrm{~g}$ ash)

\begin{tabular}{|l|c|c|c|}
\hline \multirow{2}{*}{ Элемент } & \multicolumn{3}{|c|}{ Фенологическая фаза } \\
\cline { 2 - 4 } & Бутонизация & Цветение & Плодоношение \\
\hline Натрий & $0,55 \pm 0,01$ & $0,75 \pm 0,01$ & - \\
\hline Магний & $4,47 \pm 0,03$ & $3,44 \pm 0,05$ & $2,14 \pm 0,03$ \\
\hline Алюминий & $0,72 \pm 0,01$ & $0,60 \pm 0,01$ & $0,72 \pm 0,01$ \\
\hline Кремний & $10,80 \pm 0,05$ & $14,40 \pm 0,06$ & $10,42 \pm 0,02$ \\
\hline Фосфор & $3,26 \pm 0,03$ & $1,98 \pm 0,03$ & $3,18 \pm 0,02$ \\
\hline Сера & $1,35 \pm 0,03$ & $0,75 \pm 0,02$ & $0,44 \pm 0,01$ \\
\hline Хлор & $0,52 \pm 0,02$ & $0,42 \pm 0,01$ & $0,28 \pm 0,01$ \\
\hline Калий & $25,19 \pm 0,09$ & $17,75 \pm 0,06$ & $19,91 \pm 0,05$ \\
\hline Кальций & $24,27 \pm 0,07$ & $28,22 \pm 0,10$ & $32,50 \pm 0,08$ \\
\hline Медь & $4,34 \pm 0,03$ & $2,18 \pm 0,04$ & $1,22 \pm 0,01$ \\
\hline Цинк & $1,47 \pm 0,02$ & $1,87 \pm 0,03$ & $1,98 \pm 0,02$ \\
\hline
\end{tabular}

Кальций участвует в углеводном и белковом обмене растений, образовании и росте хлоропластов, необходим для нормального усвоения растением аммиачного азота. От содержания кальция зависит построение нормальных клеточных оболочек [15]. Данный элемент накапливается в листьях воробейника лекарственного в течение всего периода развития растения, а в фазу плодоношения его содержание составляет 32,50 \pm 0,08 г/100 г золы. 
Калий, выполняя важную физиологическую функцию в углеводном и белковом обмене растений, в процессах фотосинтеза и водного обмена, повышает устойчивость растения к увяданию и преждевременному обезвоживанию, укрепляет его ткани и делает их более устойчивыми к болезням и вредителям. Наибольшее количество калия в листьях воробейника лекарственного наблюдается в период бутонизации.

В листьях воробейника лекарственного в достаточных количествах обнаружены медь и цинк, которые выполняют важную биохимическую функцию [19]. Данные элементы имеют разные тенденции накопления: наибольшее количество меди в листьях воробейника лекарственного отмечается в фазу бутонизации, а содержание цинка достигает максимального значения в период плодоношения.

Натрий относится к элементам, которые условно необходимы растениям. В химическом и физиологическом отношении натрий близок к калию. Калий может практически всегда заменить натрий, однако сам натрием не заменяется [15]. В листьях воробейника лекарственного натрий обнаружен в достаточно низком количестве, а в фазу плодоношения он вовсе отсутствует. При этом содержание калия в период плодоношения несколько увеличивается по сравнению с его содержанием в период цветения.

Заключение. Изучена динамика накопления флавоноидов в листьях воробейника лекарственного (Lithospermum officinale L.) в различные фенологические фазы. Максимальное количество флавоноидов установлено в фазу цветения $-2,53 \pm 0,11$ \% от массы абсолютно сухого сырья. Качественный состав экстрактов листьев воробейника лекарственного в различные фенологические фазы изменялся незначительно. Флавоноид изокверцитрин идентифицирован на всех стадиях развития растения, однако максимальное его накопление наблюдалось в фазу цветения. Следовательно, оптимальным временем заготовки листьев воробейника лекарственного является фаза массового цветения.

Проведен сравнительный анализ элементного состава золы листьев воробейника лекарственного, заготовленных в различные фенологические фазы. Определено количественное содержание 11 макро- и микроэлементов, преобладающими из которых на каждом этапе развития растения являлись кальций, калий и кремний.

\section{Список использованных источников}

1. Основы биохимии вторичного обмена растений / Г. Г. Борисова [и др.]. - Екатеринбург : Изд-во Урал. ун-та, 2014. - $128 \mathrm{c}$.

2. Медведев, С. С. Физиология растений / С. С. Медведев. - СПб. : БХВ-Петербург, 2012. - 512 с.

3. Филипцова, Г. Г. Основы биохимии растений / Г. Г. Филипцова, И. И. Смолич. - Минск : БГУ, 2004. -136 с.

4. Флавоноиды: биохимия, биофизика, медицина / Ю. С. Тараховский [и др.]. - Пущино : Synchrobook, 2013. - 310 c.

5. Макаренко, О. А. Физиологические функции флавоноидов в растениях / О. А. Макаренко, А. П. Левицкий // Физиология и биохимия культурных растений. - 2013. - Т. 45, № 2. - С. 100-112.

6. Brown, J. E. Flavonoids: chemistry, biochemistry and applications / J. E. Brown, M. Andersen, K. R. Markham. Boca Ratton : CRC Press, 2006. - 1197 p.

7. Parr, A. J. Phenols in the plant and man. The potential for possible nutritional enhancement of the diet by modifying the phenols content or profile / A. J. Parr, G. P. Bolwell // J. Sci. Food Agric. - 2000. - Vol. 80, N 7. - P. 985-1012. https://doi. org/10.1002/(SICI)1097-0010(20000515)80:7<985::AID-JSFA572>3.0.CO;2-7

8. Mierziak, J. Flavonoids as important molecules of plant interactions with the environment / J. Mierziak, K. Kostyn, A. Kulma // Molecules. - 2014. - Vol. 19, N 10. - P. 16240-16265. https://doi.org/10.3390/molecules191016240

9. Красная книга Республики Беларусь [Электронный ресурс]. - Режим доступа: http://redbook.minpriroda.gov.by/ plantsinfo.html?id=85. - Дата доступа: 27.01.2021.

10. Гаммерман, А. Ф. Лекарственные растения (растения-целители) : справ. пособие / А. Ф. Гаммерман, Г. Н. Кадаев, А. А. Яценко-Хмелевский. - 4-е изд. - М. : Высш. школа, 1990. - 544 с.

11. Условия экстракции и идентификации флавоноидов, стимулирующих регенерацию тканей / Е. В. Феськова [и др.] // Тр. БГТУ. Сер. 2, Химические технологии, биотехнологии, геоэкология. - 2019. - № 1. - С. $49-53$.

12. Stimulation of neuroregeneration by flavonoid glycosides [Electronic resource]. - Mode of access: www.google.com/ patents/US20120087980. - Date of access: 30.01.2021.

13. Evaluation of the wound healing potential of isoquercetin-based cream on scald burn injury in rats / N. Bhatia [et al.] // Burns and Trauma. - 2016. - Vol. 4. https://doi.org/10.1186/s41038-016-0032-1 
14. Шамсутдинова, С. Р. Определение содержания макро- и микроэлементов в сырье бодяка полевого в разных фазах вегетации растения / С. Р. Шамсутдинова, К. А. Пупыкина // Башкир. хим. журн. - 2015. - Т. 22, № 3. - С. 70-72.

15. Володько, И. К. Микроэлементы и устойчивость растений к неблагоприятным факторам среды / И. К. Володько. - Минск : Наука и техника, 1983. - 192 с.

16. Определение элементного состава травы некоторых растений / Н. Н. Бойко [и др.] // Управління, економіка та забезпечення якості в фармації. - 2015. - № 1. - С. 19-25.

17. Государственная фармакопея Республики Беларусь разработана на основе Европейской фармакопеи (ГФ. РБ ІІ) : в 2 т. / М-во здравоохранения Респ. Беларусь, РУП «Центр экспертиз и испытаний в здравоохранении». - Молодечно : Тип. «Победа», 2016. - Т. 2 : Контроль качества субстанций для фармацевтического использования и лекарственного растительного сырья. $-1367 \mathrm{c}$.

18. Адамцевич, Н. Ю. Влияние параметров экстракции на выход флавоноидов из листьев воробейника лекарственного (Lithospermum officinale L.) / Н. Ю. Адамцевич, В. С. Болтовский, В. В. Титок // Вес. Нац. акад. навук Беларусі. Сер. біял. навук. - 2020. - Т. 65, № 4. - С. 402-411.

19. Особенности накопления макро- и микроэлементов в надземной части Filipendula Ulmaria (L.) Maxim в разные фенологические фазы / И. Д. Зыкова [и др.] // Химия раст. сырья. - 2013. - № 2. - С. 189-193.

\section{References}

1. Borisova G. G., Ermoshin A. A., Maleva M. G., Chukina N. V. Fundamentals of biochemistry of secondary plant metabolism. Yekaterinburg, Ural University Publishing House, 2014. 128 p. (in Russian).

2. Medvedev S. S. Plant physiology. Saint Petersburg, BHV-Petersburg Publ., 2012. 512 p. (in Russian).

3. Filiptsova G. G., Smolich I. I. Fundamentals of plant biochemistry. Minsk, Publishing house of the Belarusian University, 2004. 136 p. (in Russian).

4. Tarakhovskii Yu. S., Kim Yu. A., Abdrasilov B. S., Muzafarov E. N. Flavonoids: biochemistry, biophysics, medicine. Pushchino, Synchrobook Publ., 2013. 310 p. (in Russian).

5. Makarenko O. A., Levitskii A. P. Physiological functions of flavonoids in plants. Fiziologiya i biokhimiya kul'turnykh rastenii [Physiology and biochemistry of cultivated plants], 2013, vol. 45, no. 2, pp. 100-112 (in Russian).

6. Brown J. E., Andersen M., Markham K. R. Flavonoids: chemistry, biochemistry and applications. Boca Ratton, CRC Press Publ., 2006. 1197 p.

7. Parr A. J., Bolwell G. P. Phenols in the plant and man. The potential for possible nutritional enhancement of the diet by modifying the phenols content or profile. Journal of the Science of Food and Agriculture, 2000, vol. 80, no. 7, pp. $985-1012$. https://doi.org/10.1002/(SICI)1097-0010(20000515)80:7<985::AID-JSFA572>3.0.CO;2-7

8. Mierziak J., Kostyn K., Kulma A. Flavonoids as important molecules of plant interactions with the environment. Molecules, 2014, vol. 19, no. 10, pp. 16240-16265. https://doi.org/10.3390/molecules191016240

9. The Red Book of the Republic of Belarus. Available at: http://redbook.minpriroda.gov.by/plantsinfo.html?id=85 (accessed 27.01.2021) (in Russian).

10. Gammerman A. F., Kadaev G. N., Yatsenko-Khmelevskii A. A. Medicinal plants (Healing plants). 4th ed. Moscow, Vysshaya shkola Publ., 1990. 544 p. (in Russian).

11. Fes'kova E. V., Leont'ev V. N., Ignatovets O. S., Adamtsevich N. Yu., Besarab A. Yu. Extraction conditions and identification of flavonoids which stimulate tissue regeneration. Trudy Belorusskogo gosudarstvennogo tekhnologicheskogo universiteta. Seriya 2: Khimicheskie tekhnologii, biotekhnologiya, geoekologiya [Proceedings of the Belarusian State Technological University. Series 2. Chemical engineering, biotechnologies, geoecology], 2019, no. 1, pp. 49-53 (in Russian).

12. Stimulation of neuroregeneration by flavonoid glycosides. Available at: www.google.com/patents/US20120087980 (accessed 30.01.2021).

13. Bhatia N., Kaur G., Soni V., Kataria J., Dhawan R. K. Evaluation of the wound healing potential of isoquercetin-based cream on scald burn injury in rats. Burns and Trauma, 2016, vol. 4, p. 8. https://doi.org/10.1186/s41038-016-0032-1

14. Shamsutdinova S. R., Pupykina K. A. The determination of the contents of macro- and microelements in the raw material Cirsium Arvense in different phases of the vegetation of the plant. Bashkirskii khimicheskii zhurnal [Bashkir chemical journal], 2015, vol. 22, no. 3, pp. 70-72 (in Russian).

15. Volod'ko I. K. Trace elements and plant resistance to unfavorable environmental factors. Minsk, Nauka i tekhnika Publ., 1983. 192 p. (in Russian).

16. Boiko N. N., Zaitsev A. I., Belikov K. N., Grishina E. V. Determination of the element composition of the herbs of some plants. Upravlinnia ekonomika ta zabezpechennia yakosti $v$ farmatsii [Management, economics and quality assurance in pharmacy], 2015, no. 1, pp. 19-25 (in Russian).

17. The State Pharmacopoeia of the Republic of Belarus was developed on the basis of the European Pharmacopoeia (GF. RB II). Vol. 2. Quality control of substances for pharmaceutical use and medicinal plant raw materials. Molodechno, Tipografiya "Pobeda" Publ., 2018. 1367 p. (in Russian).

18. Adamtsevich N. Yu., Boltovskiy V. S., Titok V. V. The influence of extraction parameters on the output of flavonoids from littlewale (Lithospermum officinale L.). Vestsi Natsyyanal'nai akademii navuk Belarusi. Seriya biyalagichnykh navuk= Proceedings of the National Academy of Sciences of Belarus. Biological series, 2020, vol. 65, no. 4, pp. $402-411$ (in Russian).

19. Zykova I. D., Efremov A. A., Gerasimov V. S., Leshok A. A. Features of accumulation of macro- and microelements in the aerial part of Filipendula Ulmaria (L) Maxim in different phenological phases. Khimiya rastitel'nogo syr'ya $=$ Chemistry of plant materials, 2013, no. 2, pp. 189-193 (in Russian). 


\section{Информация об авторах}

Адамиевич Наталья Юрьевна - аспирант. Белорусский государственный технологический университет (ул. Свердлова, 13a, 220006, г. Минск, Республика Беларусь). E-mail: natallia.adamtsevich@mail.ru

Феськова Елена Владимировна - канд. техн. наук, ст. науч. сотрудник. Белорусский государственный технологический университет (ул. Свердлова, 13a, 220006, г. Минск, Республика Беларусь). E-mail: lena.feskova@, mail.ru

Титок Владимир Владимирович - член-корреспондент, д-р биол. наук, доцент, директор. Центральный ботанический сад НАН Беларуси (ул. Сурганова, 2в, 220012, г. Минск, Республика Беларусь). E-mail: V.Titok@cbg.org.by

Болтовский Валерий Станиславович - д-р техн. наук, доцент, профессор. Белорусский государственный технологический университет (ул. Свердлова, 13a, 220006, г. Минск, Республика Беларусь). E-mail: v-boltovsky@, mail.ru

\section{Information about the authors}

Natallia Yu. Adamtsevich - Postgraduate student. Belarusian State Technological University (13a, Sverdlov Str., 220006, Minsk, Republic of Belarus). E-mail: natallia. adamtsevich@mail.ru

Alena V. Feskova - Ph. D. (Engineering), Senior Researcher. Belarusian State Technological University (13a, Sverdlov Str., 220006, Minsk, Republic of Belarus). E-mail: lena. feskova@mail.ru

Vladimir V. Titok - Corresponding Member, D. Sc. (Biol.), Associate Professor, Director. Central Botanical Garden of the National Academy of Sciences of Belarus (2v, Surganov Str., 220012, Minsk, Republic of Belarus). E-mail: V.Titok@cbg.org.by

Valeriy S. Boltovskiy - D. Sc. (Engineering), Associate Professor, Professor. Belarusian State Technological University (13a, Sverdlov Str., 220006, Minsk, Republic of Belarus). E-mail: v-boltovsky@mail.ru 